\title{
FINANCIAMIENTO ESPECULATIVO DE LA VIVIENDA EN COLOMBIA: UN ANÁLISIS DE LA DINÁMICA DE LOS PRECIOS, 2000-2016*
}

\author{
Recibido: 26 de octubre de 2017 - Aprobado: 17 de septiembre de 2018 \\ https://doi.org/10.22395/seec.v21n49a7 \\ Gonzalo Cómbita Mora** \\ Oscar Eduardo Pérez Rodríguez \\ María Gabriela Ramos Barrera***
}

\section{RESUMEN}

El presente trabajo estudia la dinámica de los precios de la vivienda en Colombia para el periodo 2000 a 2016. Se presentan los fundamentos teóricos no-convencionales para la determinación del precio, junto con dos estrategias cuantitativas: 1) un estudio descriptivo del mercado y la posible fragilidad financiera que ha permitido el incremento de los precios de la vivienda nueva; y 2) un modelo econométrico VEC que captura los determinantes de corto y largo plazo del precio. Se concluye que la dinámica del precio de la vivienda está influenciada por el crédito hipotecario y los costos de construcción, y presenta una fuerte relación de largo plazo entre el comportamiento actual y previo de los precios, evidentes en los escenarios financieros especulativos.

\section{PALABRAS CLAVE}

Economía monetaria de producción; precio de la vivienda; especulación.

\section{CLASIFICACIÓN JEL}

\author{
B26, G01, G12
}

\section{CONTENIDO}

Introducción; 1. Mercado de vivienda según el enfoque neoclásico; 2. Aproximación metodológica; 3. El mercado de la vivienda en Colombia; 4. Análisis econométrico del IPVN en Colombia;

5. Discusión y conclusiones; Bibliografía.

\footnotetext{
El presente trabajo es producto del proyecto "Políticas de integración regional y de intercambio comercial en América Latina: efectos sobre el crecimiento económico y el desarrollo" adscrito al Grupo de investigación Economía y Desarrollo Humano de la Universidad de La Salle, clasificación B en Colciencias, financiado por la Vicerrectoría de Investigaciones de la Universidad de La Salle, ejecutado de noviembre del 2015 a febrero del 2018.

* Economista, Fundación Universidad Central, Bogotá, Colombia. Magíster en Ciencias Económicas y Administrativas, Universidad Nacional de Colombia, Bogotá, Colombia. Doctorando en Economía, Universidad Nacional de Colombia, Bogotá, Colombia. Profesor e investigador, Programa de Economía, Facultad de Ciencias Económicas y Sociales, Universidad de La Salle, Bogotá, Colombia. Dirección: Carrera 5 \# 59ª-44, Bogotá, Colombia. Correo: gcombita@unisalle.edu.co

** Economista, Universidad Nacional de Colombia, Bogotá, Colombia. Magíster en Ciencias Económicas Universidad Nacional de Colombia, Bogotá, Colombia. Profesor e investigador, Programa de Economía, Facultad de Ciencias Económicas y Sociales, Universidad de La Salle, Bogotá, Colombia. Dirección: Carrera 5 \# 59a-44, Bogotá, Colombia. Correo: oeperez@unisalle.edu.co

*** Economista, Universidad de Los Andes, Mérida, Venezuela. Magíster en Economía; Mención Economía Cuantitativa, Universidad de Los Andes, Mérida, Venezuela. Doctoranda en Ciencias Organizacionales de la Universidad de Los Andes, Mérida, Venezuela. Profesora e investigadora, Programa de Negocios Internacionales, Facultad de Negocios, Gestión y Sostenibilidad, Institución Universitaria Politécnico Grancolombiano, Bogotá, Colombia. Dirección: Calle 57 \# 3-00, Bogotá, Colombia. Correo: mgramos@poligran.edu.co
} 


\title{
SPECULATIVE FINANCING OF HOUSING IN COLOMBIA: AN ANALYSIS OF PRICE DYNAMICS, 2000-2016
}

\begin{abstract}
This paper studies the dynamics of housing prices in Colombia from 2000 to 2016. The non-conventional theoretical foundations for price determination are presented, along with two quantitative strategies: 1) a descriptive study of the market and the possible financial fragility that has allowed the increase in prices of new housing; and 2) a VEC econometric model that captures the short and long term price determinants. The paper concludes that the dynamics of housing prices is influenced by mortgage loans and construction costs, and has a strong long-term relationship between current and previous behavior of prices, made evident in speculative financial scenarios.
\end{abstract}

\section{KEYWORDS}

Monetary production economy; housing prices; speculation.

\section{JEL CLASSIFICATION}

B26, G01, G12

\section{CONTENTS}

Introduction; 1. Housing market according to the neoclassical approach; 2. Methodological approach; 3. Housing market in Colombia; 4. Econometric analysis of the New Housing Price Index (IPVN) in Colombia; 5. Discussion and conclusions; Bibliography.

\section{FINANCIAMENTO ESPECULATIVO DA MORADIA NA COLÔMBIA: UMA ANÁLISE DA DINÂMICA DOS PREÇOS, 2000-2016}

\section{RESUMO}

O presente trabalho estuda a dinâmica dos preços da moradia na Colômbia no período de 2000 a 2016. Apresentam-se os fundamentos teóricos não convencionais para a determinação do preço, juntamente com duas estratégias quantitativas: 1) um estudo descritivo do mercado e da possível fragilidade financeira que permitiu o aumento dos preços de imóveis novos, e 2) um modelo econométrico VEC que captura os determinantes de curto e longo prazo do preço. Conclui-se que a dinâmica do preço da moradia é influenciada pelo crédito hipotecário e pelos custos de construção, além de apresentar uma forte relação de longo prazo entre o comportamento atual e prévio dos preços, evidentes nos cenários financeiros especulativos.

\section{PALAVRAS-CHAVE}

Economia monetária de produção; preço da moradia; especulação.

\section{CLASSIFICAÇÃO JEL}

B26, G01, G12

\section{CONTEÚDO}

Introdução; 1. Mercado de imóveis segundo o enfoque neoclássico; 2. Aproximação metodológica; 3. O mercado da moradia na Colômbia; 4. Análise econométrica dos índices de preços de moradia na Colômbia; 5. Discussão e conclusões; Bibliografia. 


\section{INTRODUCCIÓN}

En el periodo que comprende del 2001 al 2007, la economía colombiana -al igual que sus semejantes latinoamericanas- vivió un boom en su tasa de crecimiento. Este desempeño macroeconómico lo jalonó la dinámica del sector minero y petrolero, fruto del auge en el precio de los commodities (materia prima o productos básicos), así como la expansión significativa del sector constructor. La apreciación exuberante del precio de la vivienda como un activo ha sido un hecho innegable producto del éxito macroeconómico de la economía colombiana durante la primera década del siglo XXI, pero puede constituir una victoria pírrica. El fuerte incremento de los precios y costos de financiamiento pueden también significar un empeoramiento de la distribución del ingreso de los hogares a favor de las empresas constructoras y del sistema financiero. Otra dificultad es que el crecimiento económico descansaría en un sector dependiente de la continua valorización y expansión de la demanda vía crédito, además de que no aporta mucho en términos de innovación y sofisticación.

Este artículo estudia la dinámica que presentan los precios de la vivienda durante los últimos años en Colombia a partir del análisis de economías monetarias de producción, en las cuales el papel del dinero y el crédito son fundamentales para entender el comportamiento de la demanda agregada y, por ende, de las variables macroeconómicas como desempleo, producción, y en este caso, los precios. Se resalta que el rol creciente del mundo financiero no solo explica las fluctuaciones de la actividad económica, sino la especulación en los mercados de activos financieros y reales como la vivienda. La más reciente crisis del 2008 en el mundo desarrollado, y la de 1999 para el caso colombiano, son un ejemplo claro del impacto de la sobrevaloración del mercado inmobiliario en un contexto liderado por la demanda agregada, financiada en exceso por la deuda.

Para realizar la indagación de las hipótesis antes mencionadas se estimó un vector de corrección de errores -VEC- para el periodo comprendido entre el 2000 y el 2016. Con esta estimación, a diferencia de otros trabajos, se muestra que la dinámica del precio del sector constructor en Colombia no obedece a una dinámica determinista tipo causa y efecto, por el contrario, esta se explica sobre todo por la trayectoria misma del precio, lo que muestra un comportamiento especulativo convencional de procesos de apreciación de activos reales y financieros. Por otro lado, se encontró que la dinámica de la demanda agregada monetaria impulsada por el crédito juega un rol estadísticamente significativo en el incremento del precio de la vivienda. Así mismo, se evidenció que los costos de construcción jugaron un papel importante en la trayectoria de los precios de la vivienda, aunque la causalidad entre estas variables puede ser bidireccional. 
Este documento tiene cinco secciones, incluyendo la presente. La segunda es el análisis teórico alternativo para estudiar el precio del mercado de vivienda, la tercera es el análisis descriptivo en el cual se muestran algunas características esenciales del precio de la vivienda; la siguiente contiene el modelo econométrico junto con los principales hallazgos empíricos y por último, se presentan las conclusiones del trabajo.

\section{MERCADO DE LA VIVIENDA SEGÚN EL ENFOQUE NEOCLÁSICO}

El mercado de vivienda se analiza desde la teoría neoclásica ${ }^{1}$ y la figura del agente racional representativo, tanto por el lado de la oferta como de la demanda, que supone un óptimo comportamiento a partir de la función de producción, la restricción que imponen los costos, la función de utilidad y su restricción presupuestal. El proceso de optimización mencionado conduce a obtener la cantidad óptima demandada de vivienda y su precio en equilibrio.

Al maximizar la utilidad se encuentra la cantidad óptima demandada de vivienda y de suponer un stock de vivienda dada, se puede conjeturar los determinantes del precio de la vivienda²:

$$
\begin{gathered}
\mathrm{H}^{d^{*}}=\frac{\eta \mathrm{Y}}{(r+\delta) \mathrm{P}^{\mathrm{H}}} ; \mathrm{H}^{d^{*}}=\mathrm{F}(\underset{(+)}{\mathrm{Y}}, \underset{(-)}{r}, \underset{(-)}{\delta,}, \underset{(-)}{\mathrm{H}}) \\
\mathrm{P}^{\mathrm{H}^{*}}=\frac{\eta \mathrm{Y}}{(r+\delta) \mathrm{H}}
\end{gathered}
$$

La cantidad óptima de vivienda está en función del ingreso del individuo (Y), la depreciación $(\delta)$, el tipo de interés de los créditos hipotecarios (r), las preferencias por el consumo de vivienda $(\eta)$ y el precio de vivienda $\left(\mathrm{P}^{\mathrm{H}}\right)$. A su vez, el ingreso del individuo, la depreciación, el tipo de interés de los créditos hipotecarios y el stock (existencias) de vivienda hacen parte de los determinantes del precio de la vivienda. Las variables antes enunciadas constituyen las variables fundamentales del mercado de vivienda, por lo que los estudios empíricos que buscan constatar la presencia de burbujas o la caracterización del mercado, como los de Clavijo, Janna y Muñoz (2005), Salazar et al. (2013), y Hernández y Piraquive (2014), esperan que una

La teoría neoclásica o marginalista constituye lo que Lavoie (2014) resalta como el pensamiento dominante en economía, pasando por encima del pluralismo de métodos y formas de pensar de escuelas como la post keynesiana, evolucionista, austriaca, feminista, etc.

2 Este resultado se puede evidenciarse en el libro Introducción a la macroeconomía avanzada de Sorensen y Whitta-Jacobsen (2009). 
parte considerable del comportamiento de los precios y de la demanda de vivienda se explique por los fundamentales.

Así, una trayectoria explosiva de precios como la alcanzada en Bogotá después del 2007, desde la perspectiva microeconómica comentada anteriormente, se sustenta en un incremento excepcional de los fundamentales, que se respalda en las decisiones racionales bien calculadas por parte del agente representativo optimizador, lo que descarta comportamientos especulativos. Vale la pena mencionar que los movimientos especulativos que conducen a crisis inmobiliarias pueden ser explicados por el esquema teórico neoclásico siguiendo un patrón de optimización del agente representativo en condiciones de imperfecciones de mercado; por ejemplo, Shiller (2015) muestra que la valoración exagerada de activos como la vivienda puede darse en condiciones de sesgos cognitivos que explicarían el comportamiento errático de los consumidores.

\subsection{Dificultades neoclásicas}

En condiciones de intercambio puro y competencia perfecta no se necesita de ningún intermediario, excepto por el precio que regula las decisiones de oferta y demanda en este mercado, es decir, el financiamiento de la vivienda sucede mediante una transferencia directa entre las familias y las empresas constructoras coordinadas por la tasa de interés real. Sin embargo, la única posibilidad de incorporar una entidad financiera -como un banco- a este escenario surge en presencia de información asimétrica, dado que estas entidades estarían en capacidad de reducirla y facilitar el flujo de ahorro familiar a los empresarios inversionistas (Bertocco, 2007). En el caso específico del mercado inmobiliario, se asume que la creación de contratos fiduciarios impide que un constructor especule con los precios, ya que la realización de los proyectos depende de que un número significativo de agentes valide el costo al que se ofrece la vivienda, lo cual implica que dicho proyecto solo se podría realizar en el momento en que el mercado conozca el proyecto y acepte su precio.

Además, la teoría neoclásica supone que el rol del dinero es facilitar el intercambio de bienes, y que no tiene un vínculo directo con el financiamiento (ahorro), ni mucho menos con las decisiones de inversión, producción y empleo. Según Bertocco (2007), lo anterior puede verse en los efectos diferenciados que causa un aumento del dinero y el ahorro; el primero genera presiones inflacionarias, mientras que el segundo no, pues por medio de la caída en la tasa de interés se produce un efecto de desplazamiento entre el consumo y la inversión que mantiene la demanda en su mismo nivel. Un aspecto relevante de esto es que la tasa de interés que se asuma como la de equilibrio, no solo equilibra el mercado de fondos prestables, 
sino que asegura el pleno empleo en el mercado de bienes. Además, la consecución del pleno empleo asegura que la incertidumbre sobre los proyectos de inversión se puede reducir a cero por medio del riesgo probabilístico, dado que se supone que en promedio, el proceso de acumulación capitalista goza de un alto grado de estabilidad (Sheehan, 2009).

Por último, la presentación del mercado de vivienda en esta corriente teórica se hace de manera aislada, si se supone que el resto de la economía se encuentra en condiciones de equilibrio. Este es un tratamiento genérico de esta corriente de pensamiento dada al analizar los mercados por separado con base en micro fundamentos, si se asume ceteris paribus en el resto de los mercados de la economía. Esto puede ser grave en el tratamiento de las crisis del mercado inmobiliario, dado la comprobada fuerza de arrastre de este sector en el resto de la economía, incluso a nivel global, como sucedió en la crisis financiera de Estados Unidos del 2008. Este error se conoce como falacia de composición ${ }^{3}$.

\subsection{Las burbujas como eventos regulares del sistema}

Cuando un mercado particular entra en un proceso de auge y jalona un aumento en el precio de los activos relacionados, se atrae a una mayor cantidad de demandantes hacia el mismo. En una primera etapa, solo inversionistas informados ingresan al mercado, en su mayoría con recursos propios. Posteriormente, gracias a los cambios estructurales que generalizan los canales de información y facilitan las transacciones financieras, se estimula que en el momento en el que las ganancias elevadas aparezcan, más actores ingresen al mercado, sin importar su grado de conocimiento sobre el mismo o el grado de apalancamiento que deban asumir para su ingreso. Esta entrada de inversionistas valida las ganancias de los precursores del proceso, al tiempo que continúa el incremento del riesgo.

Depende del sistema financiero generar los recursos suficientes para eliminar cualquier restricción de liquidez que enfrenten los nuevos demandantes en esta segunda entrada de compradores al mercado, al tiempo que se establecen condiciones propicias para dinamizar el mercado que considere más pertinente para obtener una elevada y rápida ganancia (García, 2010).

En este entorno en el cual el costo del capital se reduce gracias a la acción del sistema financiero, la rentabilidad neta del activo se eleva en la medida en que su precio sea mayor. Esto incentiva un alza en la demanda en la medida en que dicho precio incremente, es decir, se genera un cambio en la pendiente de la curva de

\footnotetext{
3 Keen (2014) da una definición general de falacia de composición cuando muestra que es un fenómeno en el cual erróneamente se construye la explicación de un sistema a partir de sus partes y se ignora que de la escala del evento emergen situaciones distintas y complejas.
} 
demanda del mercado, y hace que esta adquiera una pendiente positiva, como se evidencia en la Figura la), en la cual la curva de demanda pasa de D (curva con pendiente convencional) a D1 (curva de pendiente positiva). Esto desemboca en una mayor presión en los precios, lo que desencadena el alza definitiva y consolida la existencia de la burbuja. El resultado de este proceso es un aumento en la adjudicación de créditos hipotecarios, en medio del aumento del riesgo moral, toda vez que los bancos tienen incentivos para otorgar créditos de forma independiente a la capacidad de pago del deudor.

Figura 1. Burbujas y mecanismos de mercado

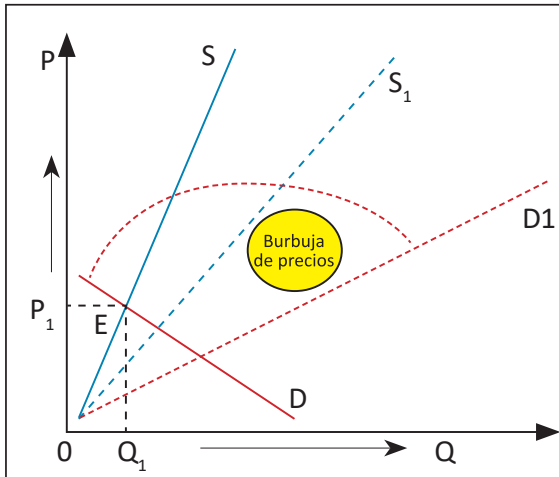

(a)

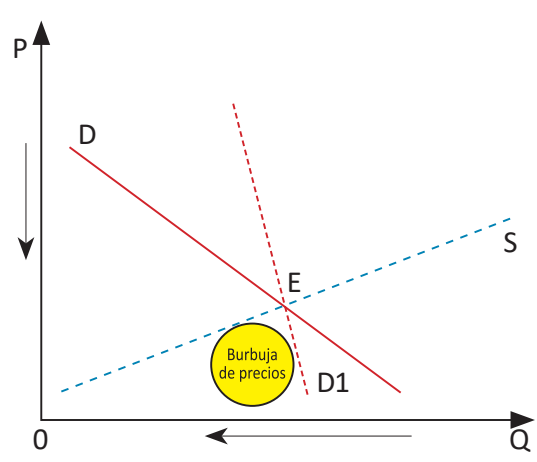

(b)

Fuente: Tyc (2013)

Al tiempo, con este aumento de la demanda los productores enfrentan condiciones más favorables por lo que la oferta también sufre un incremento y se desplaza de $\mathrm{S}$ a S1. No obstante, este incremento de la oferta resulta normalmente insuficiente, por lo cual el exceso de demanda se cubre mediante un precio excesivo que supera el valor real del activo (diferencia que se puede considerar como el tamaño de la burbuja (en la figura la se demarca con el círculo amarillo).

Acorde con el planteamiento de Minsky (1986), lo anterior refleja un deterioro de la posición deudora de los agentes que los encamina hacia una situación no cubierta de su endeudamiento en la cual se pierde la capacidad de cubrir con ingresos propios el capital y los costos de financiación en los que, por último, se genera la imposibilidad de pagar las deudas adquiridas. En este momento en que los agentes se enfrentan a la imposibilidad de cubrir sus obligaciones, los bancos cierran sus canales de crédito, con lo que generan una presión a la baja en la demanda de vivienda. 
En la figura 1b) se aprecia cómo la caída de la demanda por la contracción del crédito (que de hecho hace que la curva de demanda vuelva a adoptar una pendiente negativa), y el aumento de la oferta generada por aquellos agentes que buscan vender el activo para liquidar las deudas ${ }^{4}$, propician la caída de los precios y se configura el estallido de la burbuja. Tras este estallido, el mercado regresa a su equilibrio, pero con un nivel de precios inferior a la inicial, dada la menor elasticidad de la demanda a causa de la caída del ingreso durante la crisis generada por el fin de la burbuja de precios.

\subsection{Una visión alternativa del mercado de vivienda}

A diferencia de la teoría neoclásica, el análisis del mercado de vivienda en este trabajo adopta un enfoque post keynesiano que supone, en principio, un cambio sustancial en las variables relevantes, así como la causalidad y relacionamiento de las mismas, basado en una visión distinta del dinero, las expectativas, el equilibrio y la micro-fundamentación. Así, el reciente auge del sector vivienda se explica bajo un escenario macroeconómico de creciente fragilidad sistémica, que descansa en un fuerte endeudamiento del sector privado, una acelerada desindustrialización, junto con mayores niveles de fragilidad financiera en la balanza de pagos. De este modo, el crecimiento sostenido del precio de la vivienda no obedece a un desempeño robusto de los fundamentales, sino a un comportamiento esporádico y no sostenible de los mismos.

Con respecto al dinero, el post keynesianismo considera que las decisiones de demanda de los agentes, como las realizadas en consumo de vivienda o inversión empresarial, son las que impulsan la creación del dinero a través de la solicitud de créditos. Por ejemplo, Keen (2014) comenta que la expansión del crédito más el ingreso generado por la actividad económica son los reguladores de la demanda agregada y por ende, del cambio en el precio de la vivienda. En ese sentido, se rechaza la idea de que el ingreso $(\mathrm{Y})$ es la única fuente de la demanda presentada en la restricción presupuestal del modelo de optimización. Asimismo, cuando los bancos aprueban el crédito validan las propuestas de sus solicitantes, y a su vez, hacen realidad la incertidumbre propia de las apuestas de cada uno de ellos como empresarios o consumidores. En ese sentido, los bancos son creadores de incertidumbre macroeconómica, y a la vez, son validadores de los proyectos que derivan en la conformación y evolución de la estructura productiva en el sentido schumpeteriano (Bertocco, 2011).

Fisher (1933) denomina esto deflación de deuda. 
Ahora bien, las conductas, tanto de consumidores como productores en el esquema post keynesiano, no obedecen a decisiones racionales óptimas, sino que, por el contrario, están determinadas por comportamientos de manada que suelen alimentar procesos especulativos que derivan en fuertes oscilaciones de la demanda, producción y desempleo. En ese sentido, en un entorno incierto las decisiones especulativas de los agentes en la economía pueden ser validadas y alimentadas por el sistema financiero que otorga la liquidez para inflar las burbujas. En un ambiente que torna incierto, la mejor respuesta de los agentes es la toma de decisiones a partir de la observación y la imitación de aquellas acciones que se consideren exitosas, en las que se replica y generaliza cierto tipo específico de comportamientos ${ }^{5}$. En el momento en el que los agentes empiezan a actuar guiados por el espíritu de imitación ya descrito, el sistema financiero aparece para financiar dichas decisiones, y les permita consumir por encima de sus posibilidades reales de pago.

Lo anterior evidencia la no neutralidad del dinero y del sistema financiero ${ }^{6}$ que, bajo condiciones de incertidumbre, lleva la economía por una senda de crecimiento frágil que obedece a un continuo endeudamiento del sector privado (o público), hasta que algún evento desencadene el estallido de la burbuja que impulse una deflación de los precios de los activos, con el consecuente incremento del desempleo y efecto restrictivo de la producción que, por lo general, se unen a una crisis financiera. Esta idea la expusó Minsky $(1986,1992)$ con su hipótesis sobre inestabilidad financiera. Esta hipótesis es un claro ejemplo de cómo las expectativas y el dinero bancario endógeno engendran desde el auge, la semilla de la siguiente crisis a través del endeudamiento excesivo, el cual expone a los agentes económicos, hogares y firmas, en un escenario de elevada fragilidad ante cualquier cambio inesperado de los flujos de ingreso (cambio en la demanda) o egreso (cambio en la tasa de interés), y puede provocar una quiebra masiva de las firmas/hogares y sus financiadores los bancos, lo cual a su vez, arrastraría el resto de la economía a una recesión.

Cynamon, Fazzari y Setterfield (2012) interpretan la hipótesis de la inestabilidad financiera aplicada al consumo de los hogares en Estados Unidos durante los últimos treinta años, y presentan la manera en la que las preferencias endógenas de los individuos a los patrones de consumo sugeridos por su grupo social de referencia, sumado al papel de los medios de comunicación que reforzaban altos estándares de consumo, junto a un continuo empeoramiento de la distribución del ingreso durante esos años, derivó en un crecimiento significativo de la deuda de los hogares pues

5 Para una descripción más completa de esta teoría ver Lavoie (2004; 2005), entre otros trabajos relacionados.

- Contrario a la teoría neoclásica que supone que los bancos juegan un papel pasivo o neutro que solo sirve para eliminar asimetrías en la información. 
gastaban más de lo que ganaban en promedio gracias a la innovación en productos financieros de los bancos que aliviaba la restricción de las familias. Así, como indica Bresser (2014), el consumo exacerbado que incluía la compra de vivienda, y la consecuente burbuja creada en este sector y otro tipo de activos, conllevó una fragilidad financiera en los hogares estadounidenses que estalló con la crisis sub-prime de 2008, que terminó por arrasar la producción y el empleo mundiales.

Por otro lado, Kregel (2004), Amico, Fiorito, y Zelada (2012) y Bresser (2012) retoman la hipótesis de fragilidad financiera en el contexto de una economía pequeña y abierta que enfrenta problemas de enfermedad holandesa, creciente financiamiento con Inversión Extranjera Directa (IED) y otro tipo de capitales especulativos. Según estos autores el último boom de los commodities que ha experimentado América Latina, ha venido acompañado de una fuerte apreciación de la tasa de cambio, fruto de los ingresos externos, en mayor medida en la cuenta de capitales por el flujo de IED y recursos de financiamiento de corto plazo. Lo anterior provocó una enfermedad holandesa financiera (Botta, 2015). Así, las economías pasan de un superávit en cuenta corriente a un progresivo déficit que provoca la necesidad de un mayor nivel de endeudamiento, que en el caso de la IED suma la necesidad de generar mayores cantidades de divisas fruto de la repatriación de utilidades e intereses.

Según Kregel (2004), al igual que las firmas, los países en desarrollo pasan de una etapa de financiamiento cubierto a posiciones más frágiles. Durante las etapas previas a la crisis la economía en desarrollo intensifica su proceso de desindustrialización por lo que la rentabilidad de esos sectores cae en contra de otro tipo de actividades que se alimentan de las expectativas optimistas en sectores no transables como la construcción o activos financieros que terminan por ser una apuesta especulativa en un contexto de política monetaria laxa ${ }^{7}$. Así, la hipótesis principal del trabajo es que la dinámica de los precios de la vivienda en Colombia ha seguido una trayectoria especulativa en los últimos años, en un contexto de fuerte financiamiento vía crédito.

De acuerdo con lo anterior, se esperaría que las condiciones que posiblemente motivaron la subida de los precios de la vivienda descansen en incrementos del financiamiento vía crédito de dicha demanda, en un escenario de amortiguamiento de la restricción externa de la región, desencadenada por la apreciación de la cotización de los commodities, y reforzada por la entrada de capitales. A su vez, también

$7 \quad$ Bertocco (2011) plantea que para el mainstream (corriente principal o dominante) es el exceso de ahorro externo el que provoca la caída en la tasa de interés y, por ende, estimula la creación de la burbuja. No obstante, los post keynesianos consideran que es el entorno macroeconómico en un escenario de profunda incertidumbre y excesivo optimismo el que provoca una creciente elasticidad en el sistema financiero que deriva en un incremento significativo en el otorgamiento de crédito y consecuentemente, en el aumento de la cantidad de dinero. 
se presume que la constante valorización de la vivienda desencadena un proceso de apreciación continua que se aleja de los fundamentales, y entra en la lógica especulativa concebida como financiamiento vía deuda y valorización autoinducida.

\section{APROXIMACIÓN METODOLÓGICA}

La investigación propone contrastar las relaciones teóricas expuestas anteriormente con un análisis descriptivo del mercado de la vivienda y una valoración econométrica de las relaciones cuantitativas entre variables de interés para explicar el comportamiento de los precios en Colombia durante el período 2000-2016.

En primer lugar, se recolectaron datos de fuentes secundarias como el Departamento Administrativo Nacional de Estadística (DANE), el Banco de la República y la Comisión Económica para América Latina y el Caribe (Cepal). En segundo lugar, para entender la dinámica de los precios de la vivienda, se partió de un análisis descriptivo del comportamiento del nivel de precios de la vivienda, las tasas de interés hipotecarias, la cartera del sistema financiero, los términos de intercambio y las fluctuaciones de la tasa de cambio, con el fin de comprender la dinámica del sector vivienda. En tercer lugar, se planteó un modelo econométrico con vectores autoregresivos (VAR) para analizar la interacción simultánea de las variables que inciden en el comportamiento de los precios de la vivienda en Colombia. A partir de la metodología planteada por Arestis y González (2014), se estimó un modelo VAR cuya forma funcional sigue la siguiente ecuación:

$$
\mathrm{P}_{\mathrm{H} t}=\mathrm{A}_{0}+\sum_{s=1}^{n} \mathrm{~A}_{s} \mathrm{P}_{\mathrm{H} t-\mathrm{s}}+\varepsilon_{t}
$$

Donde $\mathrm{P}_{\mathrm{H}}$ es el índice de precios de vivienda nueva; $\mathrm{A}_{\mathrm{s}}$ es la matriz compuesta por otras variables de interés -a saber: índice de costos de la construcción de vivienda (ICCV), crédito hipotecario $(\mathrm{CH})^{8}$, Tasa de interés (TI), Tasa de Desempleo Nacional $(\mathrm{U})^{9}$, Ingreso Nacional per cápita (PIBpc) y Formación Bruta de Capital Fijo, (FBKF) ${ }^{10}$ - y

8 Saldo en cartera, en miles de millones de pesos.

9 En la Gran Encuesta Integrada de Hogares 2016, elaborada por el DANE, se tomaron dentro de "los desocupados" a aquellas personas que se encontraban con desempleo abierto u oculto y disponibles para laborar, mientras que para calcular la tasa de ocupados se incluyeron personas que al menos trabajaron una hora remunerada durante la recolección de datos. Como no se especifica qué proporción de ocupados tenía esta característica, y un ingreso por una hora remunerada semanal no es significativo para influir dentro del precio de la vivienda, se toma en consideración la tasa de desocupados y no la de ocupados.

10 La IED se puede vincular con la acumulación de capital de un país, pero constituye una fuente de financiamiento que no necesariamente forma parte de la FBKF. Por ello, se toma como referencia del modelo a la FBKF, dado que representa el uso de los recursos al incluir los bienes fijos adquiridos por residentes en el país (como viviendas). 
$\varepsilon_{t}$ es el vector de error aleatorio ${ }^{11}$. Con el objeto de explicar el modelo en términos de elasticidades, las variables están expresadas en logaritmos.

En términos generales, el modelo VAR explicará al vector columna del precio de vivienda, de orden $n$, con base en el elemento (i,j) de la matriz $A_{s}$, con $1 \leq s \leq n$, que medirá el efecto directo o parcial de un cambio unitario en $\mathrm{P}_{\mathrm{H}, \mathrm{j}}$ en el momento t sobre $\mathrm{P}_{\mathrm{H}, \mathrm{i}}$ en s periodos. De acuerdo con Greene (2003), la columna j de la matriz $\mathrm{A}_{\mathrm{s}}$ mide la forma en la que el cambio unitario en $Y_{j}$, en el instante $t$, influye sobre el vector $Y_{t+s}$, mientras que el elemento i-ésimo en $\varepsilon_{t}$ es el componente de $Y_{i t}$ que no puede ser previsto con observaciones pasadas de las variables que integran al vector $Y_{t}$

En otras palabras, el modelo explicará un conjunto de variables que se comprueban simultáneamente y dependen de sus propios rezagos en el tiempo.

\section{EL MERCADO DE LA VIVIENDA EN COLOMBIA}

\subsection{Evolución del precio de la vivienda}

Durante los últimos 13 años los precios de la vivienda nueva se han triplicado, mientras que el precio de la vivienda usada ha llegado al doble de su valor presentado al inicio del 2003. Mientras tanto, el costo de construcción (sin incluir el precio del suelo), ha crecido apenas un 50\% en el mismo periodo de tiempo, lo que evidencia un aumento de la tasa de ganancia de los constructores.

Tabla 1. Nivel del índice de precios

\begin{tabular}{|c|c|c|c|}
\hline Periodo \Índice & IPVU* & IPVN & ICCV \\
\hline 2003-I & 64,34 & 30,48 & 133,16 \\
\hline 2016-III & 139,55 & 114,22 & 223,63 \\
\hline
\end{tabular}

* IPVU= Índice de precios de vivienda usada; IPVN= Índice de precios de vivienda nueva; ICCV= Índice de costos de la construcción de vivienda

Fuente: elaboración y cálculos propios con datos del DANE

Adicional a esto, al observar el comportamiento de estos tres índices se observa de forma muy clara las tres fases del ciclo que presentó el sector de la vivienda desde finales de la década de los 90:

- Una primera etapa de recesión, que empieza cerca del segundo trimestre de 1998 y que se extiende hasta el primer trimestre del 2003, periodo durante el cual la

11 Es decir $\varepsilon_{t}$ son los procesos sin autocorrelación con $u \operatorname{Var}\left(u_{t}\right)=\sum$, constante (Greene, 2003). 
vivienda nueva aumentó su precio en un 0,35\% promedio trimestral, mientras que la vivienda usada redujo su precio.

- Una segunda fase de recuperación que empieza en el 2003 y se mantiene hasta finales del 2007, muestra un crecimiento promedio de 2,27\% en los precios de vivienda nueva, con lo cual el mercado retorna los niveles anteriores a la crisis en el último trimestre del 2006.

- La fase más reciente, que empieza en el 2007 y que aún no se detiene, se puede considerar una fase de auge; en esta el precio de la vivienda ha crecido a un ritmo promedio de 2,75\%. Aunque vale la pena acotar que entre el segundo semestre del 2014 y el final del 2015, los precios presentaron una desaceleración, periodo en el que crecen a un ritmo de apenas 1,62\% trimestral (frente al 3,8\% que creció en la primera parte de esta fase, entre el 2007 y 2008).

Tabla 2. Crecimiento promedio trimestral por fase del ciclo

\begin{tabular}{lccc}
\hline \multicolumn{1}{c}{ Periodo $\backslash$ Índice } & IPVU & IPVN & ICCV \\
\hline 1997-2002 (Recesión) & $-1,07$ & 0,53 & 2,47 \\
\hline 2003-2006 (Recuperación) & 1,05 & 2,27 & 1,48 \\
\hline $2007-2016$ (Auge) & 1,66 & 2,75 & 0,81 \\
\hline
\end{tabular}

Fuente: elaboración y cálculos propios con datos del DANE

A partir de estos datos se puede apreciar que el comportamiento a corto plazo de los precios de la vivienda nueva no se puede explicar por un aumento en los costos de construcción, toda vez que estos han crecido mucho menos que el precio (con excepción de la fase de recesión), pero que a largo plazo, ambas variables se mueven en un mismo sentido, lo que es muestra del peso que tienen los costos sobre el proceso de construcción, así como del impacto que tiene la mayor demanda de materiales y suelo sobre los precios de estos bienes. Sin embargo, cabe aclarar que, como muestran Garcia y otros (2016), algunos costos no son reflejados por el índice ICCV, como por ejemplo los impactos que tienen las modificaciones realizadas en los planes de ordenamiento territorial y que limitan la disponibilidad de suelo para la construcción, pero sí afectan el precio final de la vivienda.

Por otra parte, se evidencia que el precio de la vivienda usada presenta una mayor volatilidad, con una fuerte caída durante la fase recesiva, y un proceso de recuperación con algunos trimestres de rezago frente a la vivienda nueva; pese a esto, es claro el incremento. Al desagregar este comportamiento por ciudades, se encuentra que entre el 2007 y el segundo trimestre del 2014, Bogotá y Bucaramanga 
presentaron crecimientos por encima del promedio nacional $3 \%$ y 3,7\% promedio trimestral respectivamente), mientras Medellín y Cali se mantuvieron por debajo de esta cifra, con un crecimiento del 2\% promedio (durante el mismo periodo). Durante el 2015 y el 2016, mientras el mercado general se desaceleraba, solo ciudades intermedias como Popayán e Ibagué crecieron por encima del 3\% trimestral (frente a un 2\% en Bogotá y Medellín o un 1,5\% en Bucaramanga y Cali), diferencias que se presentaron entre ciudades aun cuando la dinámica de la economía capitalina (y de las demás ciudades) no se encuentra muy por encima de la del resto del país, lo cual deja sin explicación la brecha observada en los precios del sector (Pérez, 2015).

Figura 2. Índices de precios de la vivienda a nivel nacional

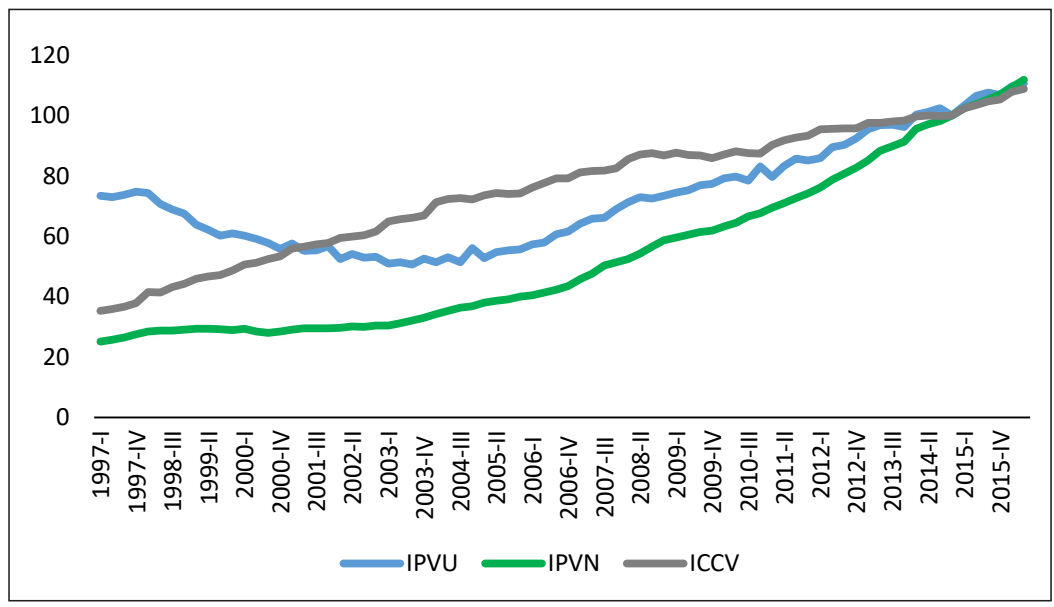

Fuente: elaboración y cálculos propios con datos del DANE

Por otra parte, se evidencia que el precio de la vivienda usada presenta una mayor volatilidad, con una fuerte caída durante la fase recesiva, y un proceso de recuperación con algunos trimestres de rezago frente a la vivienda nueva; pese a esto, es claro el incremento. Al desagregar este comportamiento por ciudades, se encuentra que entre el 2007 y el segundo trimestre del 2014, Bogotá y Bucaramanga presentaron crecimientos por encima del promedio nacional (3\% y 3,7\% promedio trimestral respectivamente), mientras Medellín y Cali se mantuvieron por debajo de esta cifra, con un crecimiento del 2\% promedio (durante el mismo periodo). Durante el 2015 y el 2016, mientras el mercado general se desaceleraba, solo ciudades intermedias como Popayán e Ibagué crecieron por encima del 3\% trimestral (frente a un 2\% en Bogotá y Medellín o un 1,5\% en Bucaramanga y Cali), diferencias que se presentaron entre ciudades aun cuando la dinámica de la economía capitalina (y de las demás ciudades) no se encuentra muy por encima de la del resto del país, lo cual deja sin explicación la brecha observada en los precios del sector (Pérez, 2015). 
Este mayor crecimiento de los precios de estas ciudades no va acompañado por un crecimiento superior en los costos, los cuales han mostrado un crecimiento similar al del resto del país, al tiempo que pequeñas disminuciones en los niveles de desempleo permitirían explicar la mayor facilidad para adquirir créditos hipotecarios y, así, elevar la demanda y los precios en estas ciudades por encima del promedio nacional.

De este análisis se desprende que los procesos de desajuste han impactado de manera diferenciada las regiones según su potencial y enfoque sectorial, donde las dos ciudades más afectadas muestran una tendencia hacia sectores más industriales y economías de servicios, frente a zonas con predominancia primaria y minera.

\subsection{Endeudamiento y estímulos al sector}

Este incremento de los precios se da paralelo a un aumento de la demanda, producto de políticas monetarias expansivas que permiten un mayor endeudamiento y de políticas específicas dirigidas a dinamizar el sector, entre las cuales se encuentran subsidios específicos sobre la tasa de interés (lo cual reduce el costo de endeudamiento y facilita aún más la entrada al mercado de agentes con poco respaldo financiero para sus hipotecas).

Figura 3. Tasas de interés hipotecarias con y sin subsidio

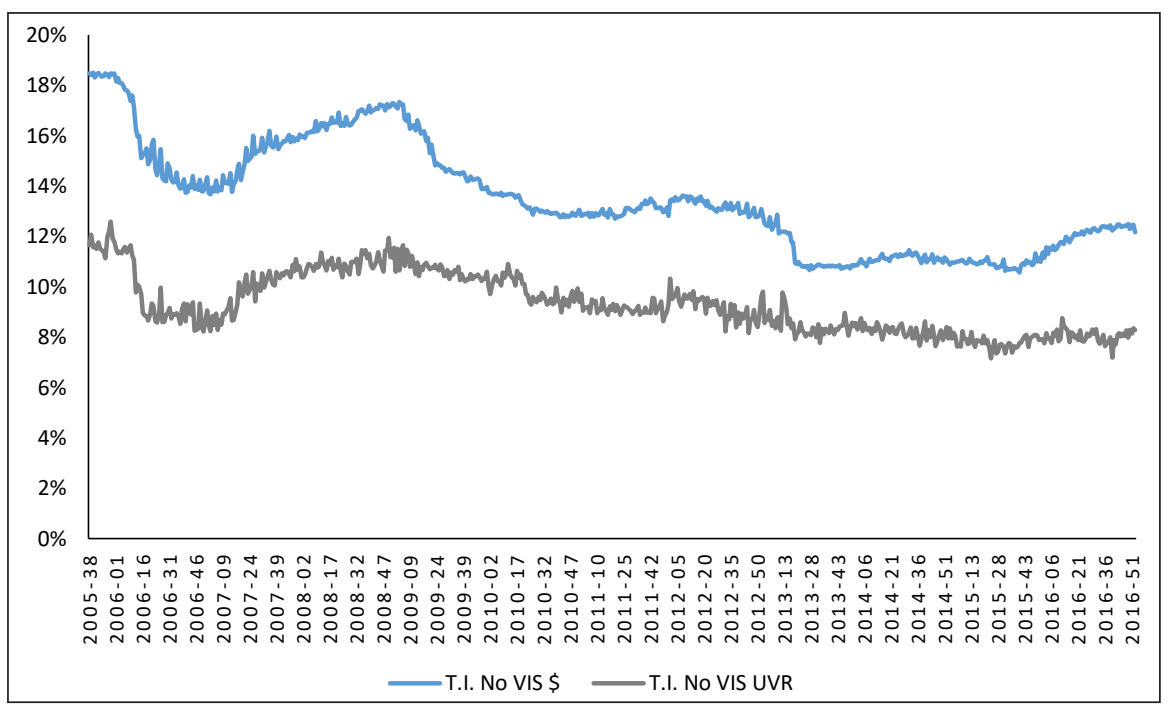

- T.I. No VIS \$ = Tasa de interés de los créditos en pesos para vivienda que no entra en la categoría de Vivienda de Interés Social (VIS)

T.I. No VIS UVR = Tasa de interés de los créditos en Unidade de Valor Real (UVR) para vivienda no VIS

Fuente: elaboración y cálculos propios con datos del Banco de la República 
Esta política expansiva tiene dos momentos clave. El primero entre el 2006 y el 2007, coincidente con la recuperación del sector, y la segunda entre el 2009 y el 2013 en que la reducción de las tasas se acompaña de la aplicación de un subsidio adicional (que va de 2,5\% a 5\%, según el tipo de vivienda y el valor de la misma). Ambos periodos coinciden con una expansión fuerte de los precios de la vivienda, lo cual puede ser evidencia de la efectividad de la política en el estímulo de la demanda y la activación del sector. Esta dinámica en las tasas de interés ha permitido una ampliación del endeudamiento, tanto en términos de la cartera hipotecaria, como la de consumo.

Figura 4. Cartera del sistema financiero

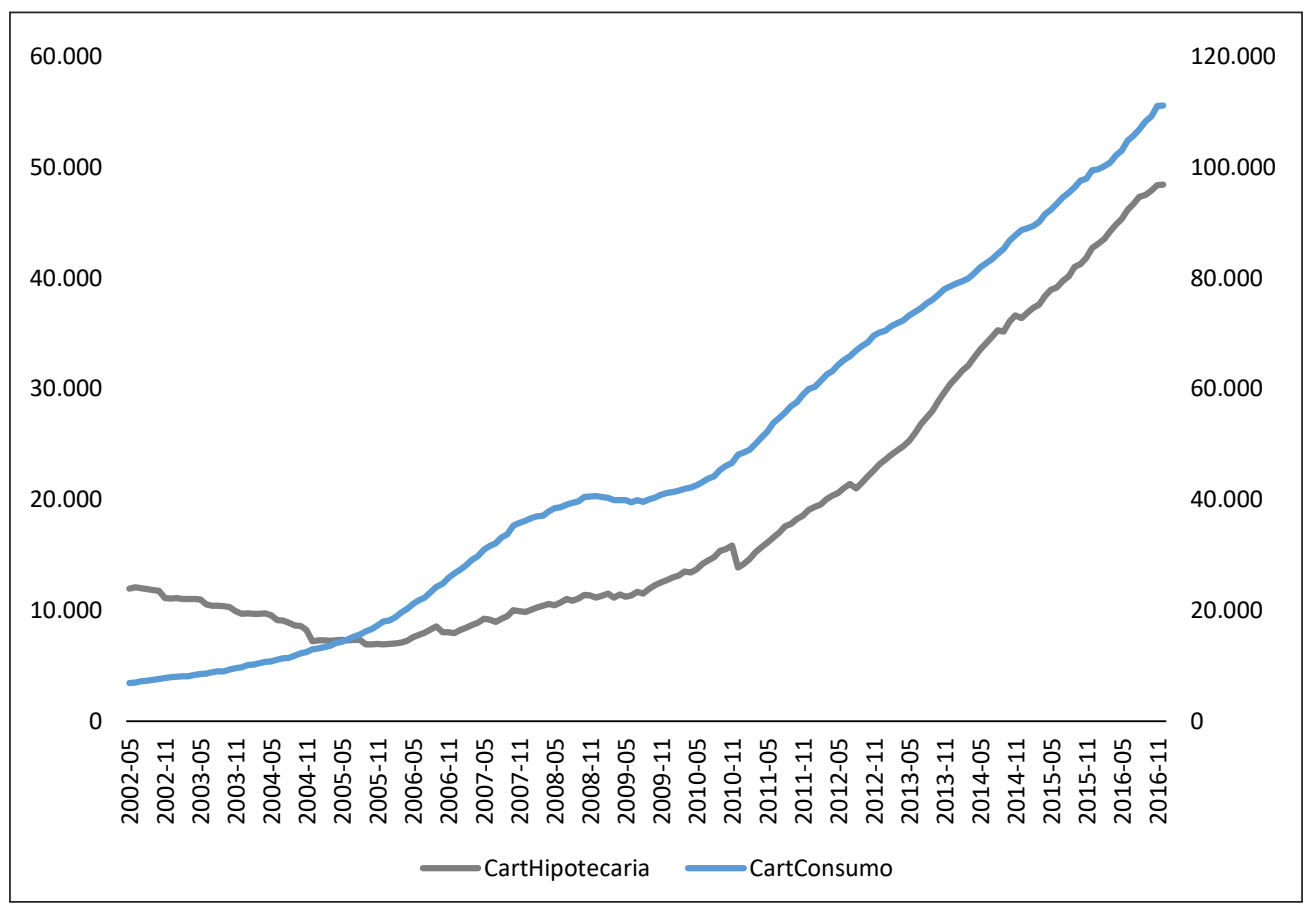

Cifras en miles de millones de pesos. En el eje derecho se muestra la cartera hipotecaria y en el izquierdo la cartera de consumo.

Fuente: elaboración y cálculos propios con datos del Banco de la República

Mientras la cartera hipotecaria ha crecido a un ritmo promedio de 1,62\% mensual desde mayo del 2008 hasta diciembre del 2016, la cartera de consumo ha aumentado a una tasa promedio de 1,06\% en el mismo periodo. Lo anterior muestra una clara correlación entre los flujos de deuda hipotecaria, y los créditos de consumo, relación que se muestra más fuerte entre los créditos de largo plazo (más de 5 años) 
y las hipotecas en pesos, concentradas en estratos medios y altos (justo donde se evidencia un mayor crecimiento de los precios de la vivienda) ${ }^{12}$.

Tabla 3. Correlación por tipo de crédito hipotecario/de consumo (diferentes plazos)

\begin{tabular}{lcccc}
\hline \multicolumn{1}{c}{ Tipo de Hipoteca / Plazos } & $31-365$ & $366-1095$ & $1096-1825$ & $>1825$ \\
\hline Hipot \$ & 0,33393726 & 0,72639361 & 0,89154754 & 0,9085046 \\
\hline Hipot UVR & $-0,05949604$ & $-0,0130241$ & $-0,23937467$ & $-0,19269771$ \\
\hline Hipot \$ VIS & 0,37221057 & 0,72413983 & 0,89698355 & 0,87922721 \\
\hline Hipot UVR VIS & 0,17889347 & 0,36862787 & 0,2256443 & 0,21910119 \\
\hline
\end{tabular}

Fuente: elaboración y cálculos propios con datos del Banco de la República

Esta correlación puede evidenciar que las restricciones impuestas sobre la necesidad de un mínimo de recursos propios para la adquisición de vivienda se están eludiendo a través del pago de una cuota inicial por medio de endeudamiento (créditos de consumo de libre inversión); es decir que los demandantes podrían adquirir viviendas a costos elevados sin contar con un nivel mínimo de ingresos propios, lo que facilita en el mediano plazo la creación de hipotecas de mala calidad.

\subsection{Sector externo}

Durante el periodo de análisis el sector externo ha vivido un periodo de boom gracias al buen desempeño de los commodities durante la primera década de este siglo. Lo anterior se puede evidenciar en la figura 5 que muestra la continua mejora en los términos de intercambio, lo que a su vez se refleja en una constante apreciación del tipo de cambio nominal, que contrario a la teoría de la Paridad del Poder Adquisitivo (PPA), ha afectado en la misma dirección la tasa de cambio nominal, lo cual se observa en la figura 6.

El boom de los commodities que ha venido acompañado de otro boom financiero en la balanza de pagos ha desencadenado la reaparición de la enfermedad holandesa con sus consecuencias contractivas en las actividades transables, especialmente en la manufactura y la agricultura (Botta, Godin, y Missaglia, 2014; Goda y Torres, 2013). Por supuesto, hizo más dependiente la economía de los ingresos petroleros junto con la cada vez mayor necesidad de financiamiento externo.

12 La vivienda en el segmento de ingresos más bajos (que incluye la vivienda de interés prioritario -VIP-) creció, en promedio, medio punto porcentual por debajo de lo que creció el precio en los segmentos medio y alto, posiblemente por la regulación más estricta de este segmento. 
Figura 5. Términos de intercambio

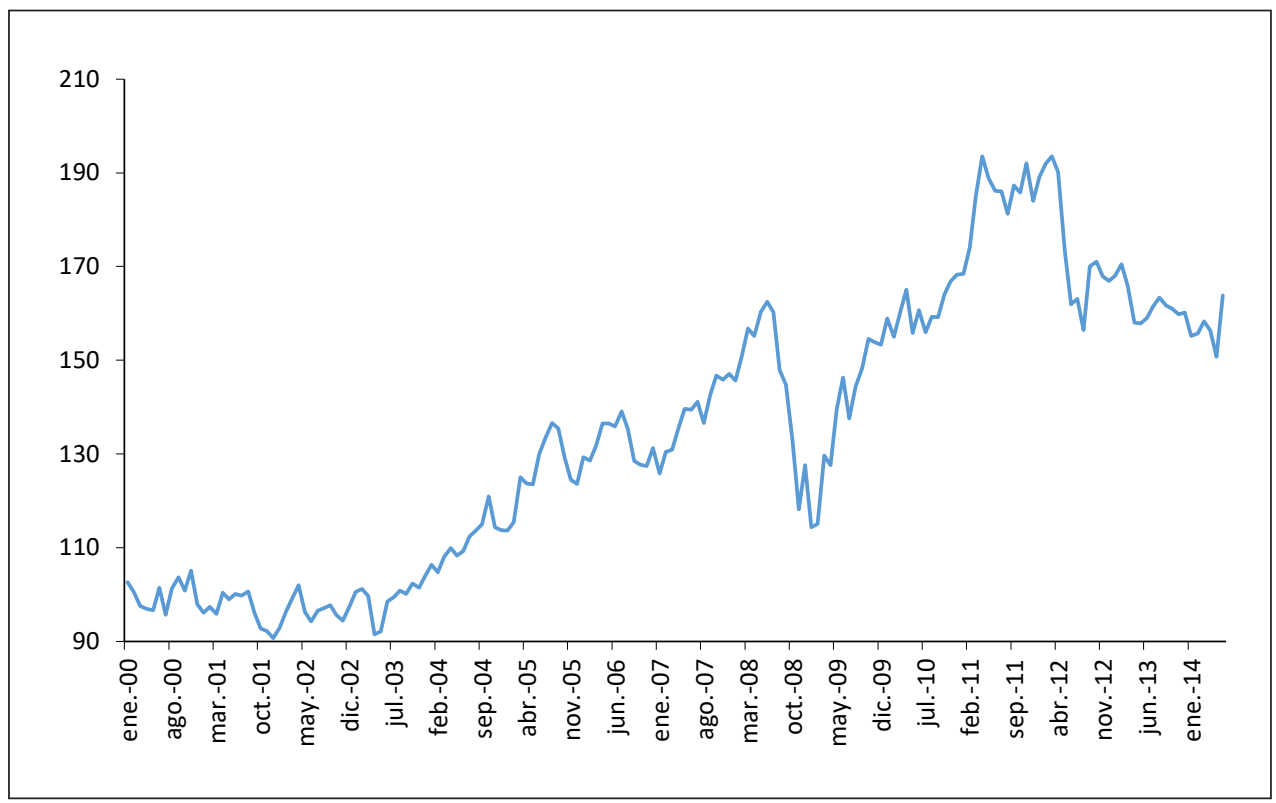

Fuente: elaboración y cálculos propios con datos del Banco de la República y la Cepal

Figura 6. Relación entre la tasa de cambio nominal y real

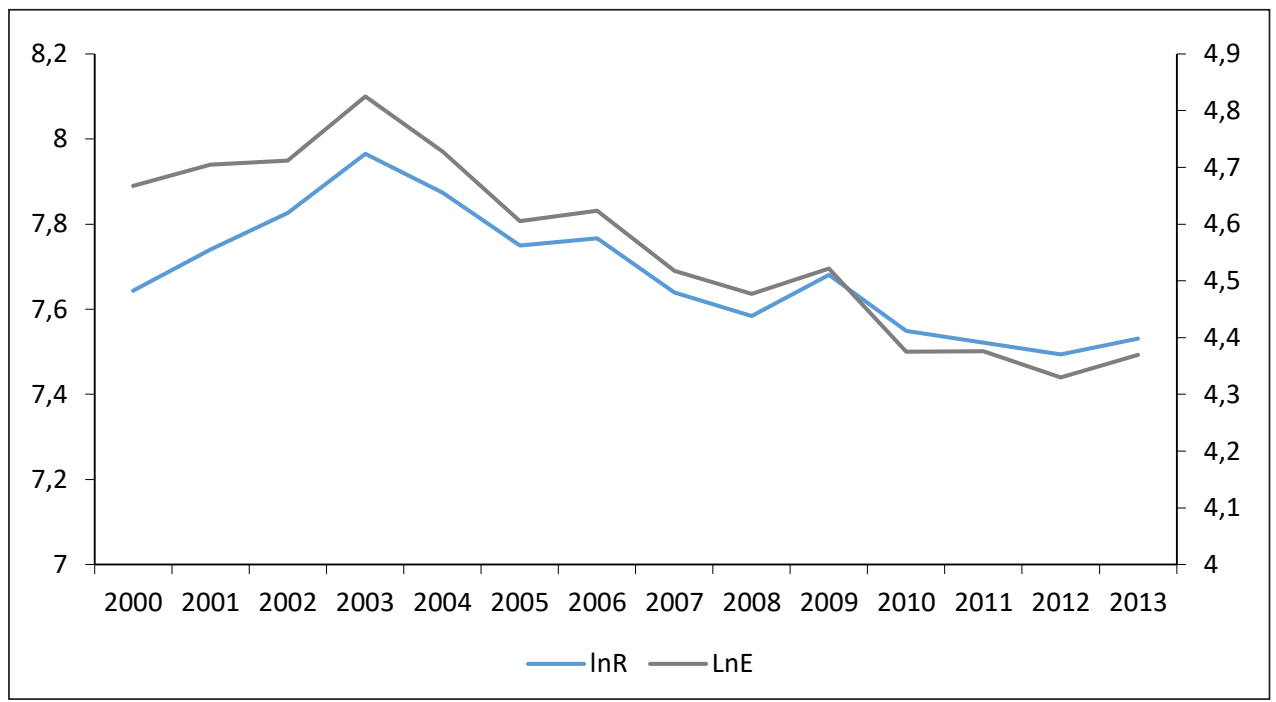

* $\mathrm{LnR}=$ logaritmo natural de la tasa de cambio real; $\mathrm{LnE}=$ logaritmo natural de la tasa de cambio nominal Fuente: cálculos propios con datos del Banco de la República y la Cepal 
La enfermedad holandesa ha significado un entorno favorable para la economía colombiana en términos de crecimiento y buena percepción de las calificadoras de riesgo a nivel internacional, lo que ha derivado en elevados niveles de financiamiento. Financiamiento que se alimenta también de la inversión extranjera directa, la cual, de acuerdo con datos del Banco de la República, pasó de 2.134 millones de dólares en el 2002 a 16.211 millones en el 2013. De este total, la inversión destinada al sector de la construcción y al sector de servicios financieros ${ }^{13}$ representa el $12 \%$ en promedio; si excluimos la inversión petrolera, estos dos sectores llegan a representar el 19,6\% del total de la inversión recibida por el país en este periodo.

Entre el 2014 y el 2015 (cuando empieza la desaceleración de la economía), estos dos sectores llegan a representar entre el 27\% y el 30\% de la IED diferente del petróleo, lo que los confirma como los sectores más atractivos para el capital extranjero que llega al país. Esta dinámica se convierte, a su vez, en un entorno interno favorable para la especulación y el crecimiento impulsado en la demanda con endeudamiento excesivo.

Por ello, el periodo de boom -que se prevé no sustentable-es el que ha permitido que sectores no transables como la vivienda, hayan crecido a ritmos excelentes durante el periodo de estudio, por lo que se plantea como hipótesis que el buen desempeño externo temporal ha traído los capitales necesarios que en condiciones de expectativas optimistas, aceleran la toma de créditos y la expansión de la demanda en sectores de baja productividad y alto nivel especulativo como la construcción.

Es importante resaltar que estos capitales no logran afectar de manera directa, ni se ven reflejados, en el ingreso medio de los hogares, pero sí en el nivel de Producto Interno Bruto (PIB) per cápita como ingresos empresariales asociados al capital, reforzando la idea de que la dinámica del sector inmobiliario no se sustenta tan solo en una demanda familiar con fines de satisfacer una necesidad primaria, sino que está altamente influenciada por una demanda con fines de inversión realizada por grandes capitales que permiten su adquisición aún con precios elevados; se desliga así el comportamiento del precio de la vivienda de la dinámica del ingreso disponible.

\section{ANÁLISIS ECONOMÉTRICO DEL IPVN EN COLOMBIA}

Con la finalidad de estimar un modelo robusto, dada la combinación de variables que presentan similitud, es necesario analizar la existencia de integración entre las variables y su orden de integración. Por ello, previo a la estimación del modelo, se

13 Este último sector incluye las actividades auxiliares de la intermediación financiera y las actividades inmobiliarias, empresariales y de alquiler, por lo cual se considera directamente relacionada con la vivienda. 
realizó la prueba de raíz unitaria de Dickey-Fuller aumentada, la cual comprobó la existencia de raíces unitarias en todas las variables (con excepción de la TI). Por tanto, el vector $\mathrm{y}_{\mathrm{t}}$ del modelo se compone de la primera diferencia del logaritmo de cada variable y el nivel del logaritmo de la TI.

Tabla 4. Prueba de raíz unitaria

\begin{tabular}{lcccc}
\hline \multirow{2}{*}{ Variable } & \multicolumn{2}{c}{ Nivel } & \multicolumn{2}{c}{ Primera diferencia (D1) } \\
\cline { 2 - 5 } & Estadístico & p-value & Estadístico & p-value \\
\hline LIPV & $-2,1181$ & 0,5250 & $-5,1490$ & 0,0005 \\
\hline LICCV & $-3,0518$ & 0,1283 & $-3,4893$ & 0,0507 \\
\hline LCH & $-2,9664$ & 0,1503 & $-6,4826$ & 0,0000 \\
\hline LTI & $-3,7968$ & 0,0237 & --- & -- \\
\hline LU & $-2,5359$ & 0,3105 & $-3,0603$ & 0,0260 \\
\hline LPIBPC & $-1,6449$ & 0,4536 & $-8,1836$ & 0,0000 \\
\hline LFBKF & $-1,7126$ & 0,7333 & $-10,2271$ & 0,0000 \\
\hline
\end{tabular}

Fuente: elaboración y cálculos propios. Se incluye tendencia e intercepto

Posteriormente, haciendo uso de las pruebas de cointegración de Johansen, se verificó que las variables son integradas en el mismo orden y también cointegradas, lo que asegura la existencia de una relación no espuria y estacionaria, es decir que se pudo verificar la hipótesis de relaciones de equilibrio entre las series en el largo plazo.

Tabla 5. Prueba de cointegración

\begin{tabular}{lcccc}
\hline \multirow{2}{*}{$\mathrm{N}^{\circ}$ de EC } & Valor propio & Estadístico & 0,05 & \multirow{2}{*}{$\begin{array}{c}\text { Prob.* } \\
\end{array}$} \\
\hline Ninguno* & 0,84915 & 235,9511 & 125,6154 & 0,0000 \\
\hline Al menos 1* & 0,56032 & 130,0303 & 95,75366 & 0,0000 \\
\hline Al menos 2* & 0,43218 & 84,01429 & 69,81889 & 0,0024 \\
\hline Al menos 3* & 0,31550 & 52,32125 & 47,85613 & 0,0179 \\
\hline Al menos 4* & 0,30588 & 31,09331 & 29,79707 & 0,0353 \\
\hline Al menos 5 & 0,14593 & 10,64682 & 15,49471 & 0,2342 \\
\hline A lo sumo 6 & 0,03186 & 1,813193 & 3,841466 & 0,1781 \\
\hline
\end{tabular}

$\left({ }^{*}\right)$ Denota el rechazo de la hipótesis al 5\%). $\quad\left({ }^{* *}\right)$ MacKinnon-Haug-Michelis p-values

Fuente: elaboración y cálculos propios. Se incluye intercepto. 
Dada la presencia de cointegración entre las variables del modelo, este se debe analizar con un mecanismo de corrección de errores (modelo VEC, por sus siglas en inglés) para representar el comportamiento dinámico de las series. Adicionalmente, con el fin de identificar el orden del rezago de la línea de regresión propuesta, se toma en consideración la minimización del criterio de información de Akaike. De lo anterior, se obtiene que la estructura de rezagos adecuada es un VEC con tres rezagos, como demuestra la Tabla 6.

Tabla 6. Rezagos adecuados

\begin{tabular}{cc}
\hline Retraso & AIC \\
\hline 0 & $-16,40393$ \\
\hline 1 & $-31,27019$ \\
\hline 2 & $-31,84844^{*}$ \\
\hline
\end{tabular}

$\left(^{*}\right)$ Indica el rezago adecuado según el criterio de Akaike (AIC)

Fuente: elaboración y cálculos propios

Con base en los resultados anteriores se calcula la ecuación de cointegración que permite estimar el equilibrio de largo plazo para los precios de la vivienda, definido por la serie estacionaria de la Tabla 7.

Tabla 7. Coeficientes normalizados de cointegración

\begin{tabular}{lccc}
\hline Variable & Coeficiente & Estadístico $t$ & Error Estándar \\
\hline LCH & 0,129741 & 11,9802 & 0,01083 \\
\hline LFBKF & 0,361432 & 8,36962 & 0,04318 \\
\hline LICCV & 1,661973 & 18,4167 & 0,09024 \\
\hline LPIBPC & $-0,203917$ & 2,47872 & 0,08227 \\
\hline LTI & $-0,048647$ & 1,22740 & 0,03963 \\
\hline LU & 0,206277 & 6,55071 & 0,03149 \\
\hline
\end{tabular}

Fuente: elaboración y cálculos propios

De lo anterior se podría inferir que los precios de la construcción poseen una relación de largo plazo significativa con los precios de la vivienda, dado que su coeficiente superior sugiere la sensibilidad de los precios de la vivienda ante cambios en los precios de la construcción. Igualmente, de la ecuación destaca la participación de la FBKF que tiene una relación positiva y significativa en el largo plazo, mientras que variables como la tasa de interés demuestran un efecto de largo plazo pequeño. 
Sin embargo, la forma más eficiente para evaluar este tipo de modelos es a través de los impulsos; como se evidencia en la figura 7, un impacto de una desviación estándar en el crédito hipotecario tendrá un impacto positivo en los precios de las viviendas nuevas hasta el sexto trimestre en el que comenzará a decrecer. Este comportamiento es similar al ocasionado por un impacto de los costos de construcción sobre los precios de vivienda nueva.

Figura 7. Funciones de respuesta al impulso instantáneo

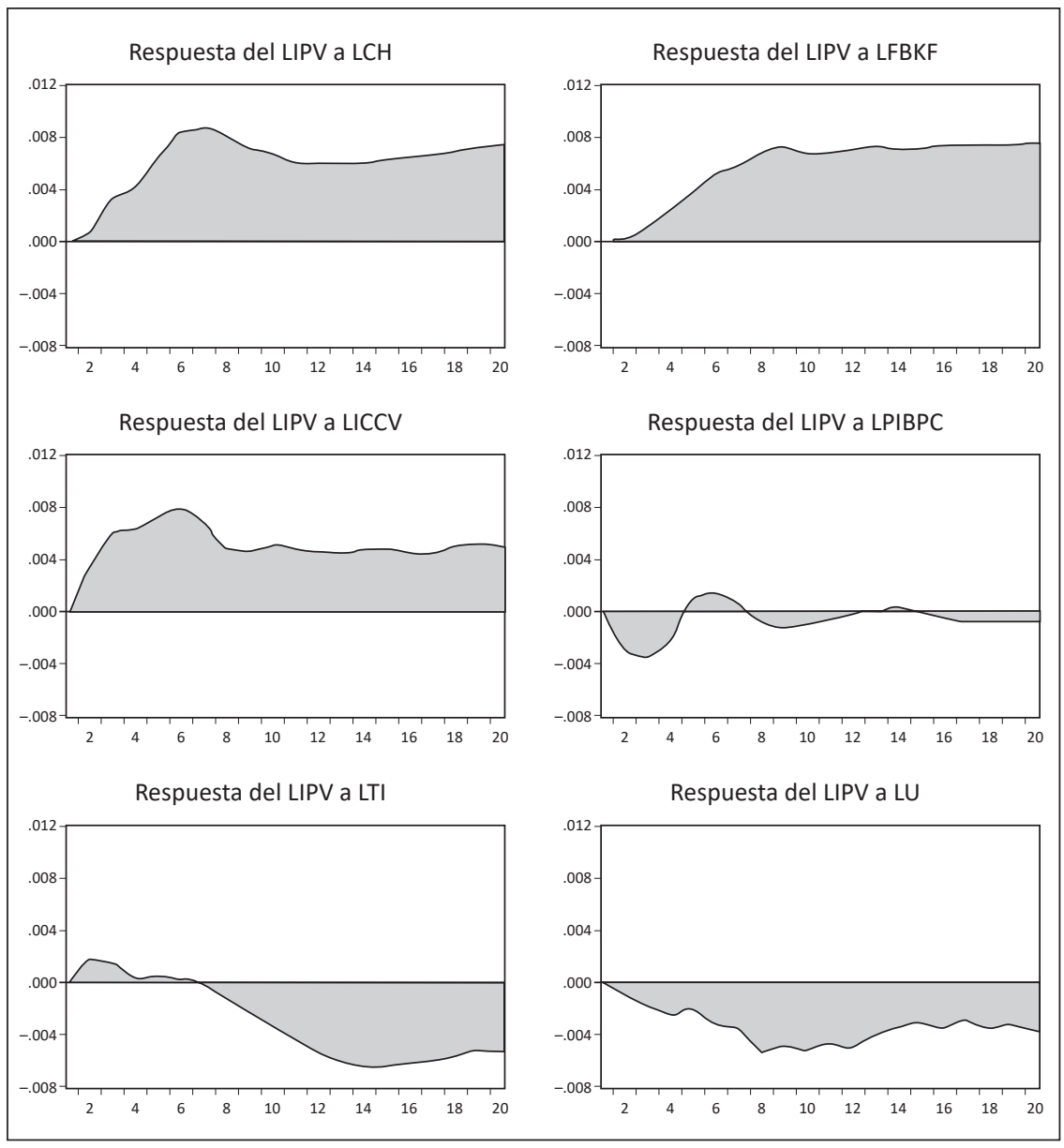

Fuente: cálculos propios, elaboración de gráficos con el programa Eviews

Con respecto al impacto que generan los ingresos nacionales per cápita sobre los precios de la vivienda, se evidencia una disminución de estos durante los tres primeros trimestres posteriores al impacto, para luego oscilar cercano a cero, lo que manifiesta insignificancia sobre el comportamiento de los precios de la vivienda. 
En cuanto al desempleo, se observa un impulso no transitorio, obteniendo (en su mayoría) impulsos decrecientes sobre el precio de la vivienda.

La figura 8 presenta la función de respuesta acumulada de los precios de la vivienda ante los choques de las demás variables incluidas en el modelo. Para el caso de los impulsos de los precios de la vivienda, los créditos hipotecarios, la formación bruta de capital fijo y los precios de la construcción, se observa un impulso positivo de carácter expansivo sobre los precios de vivienda nueva en Colombia. En el caso del desempleo se puede encontrar el mismo impulso de carácter expansivo, pero con influencia negativa.

Figura 8. Funciones de respuesta al impulso acumulado

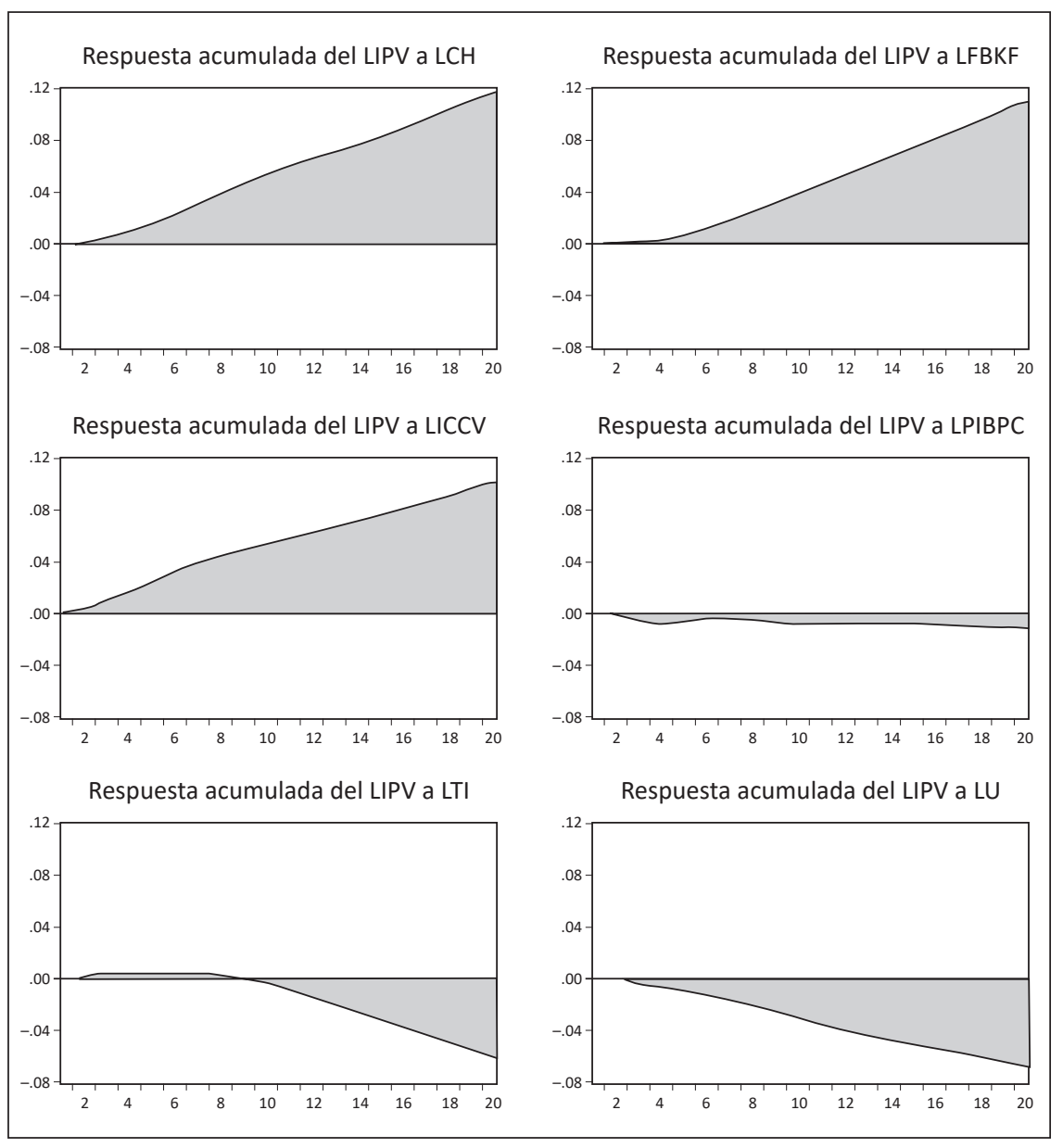

Fuente: cálculos propios, elaboración de gráficos con el programa Eviews 
Por otro lado, para la variable PIBpc no se observan comportamientos significativos, lo que iría de la mano de la hipótesis planteada previamente que señala que el ingreso de capitales acelera la expansión del crédito a través de los ingresos empresariales y no como consecuencia de la variación en el ingreso medio de los hogares.

Por otro lado, la descomposición de varianza para el logaritmo del índice de precios de vivienda nueva se resume en la figura 9. Los resultados implican que los precios de la vivienda se explican fundamentalmente por su propia variación, seguido por los créditos hipotecarios y los precios de la construcción. Se comprueba nuevamente que las tasas de interés no explican de forma significativa las variaciones del precio de la vivienda en Colombia. Vale la pena destacar que la participación de la FBKF explica, con el paso del tiempo, una mayor variación de los precios; es decir que el efecto positivo de la inversión en capital fijo sobre el nivel de precios de la vivienda en Colombia incrementa en cada trimestre.

Figura 9. Descomposición de varianza

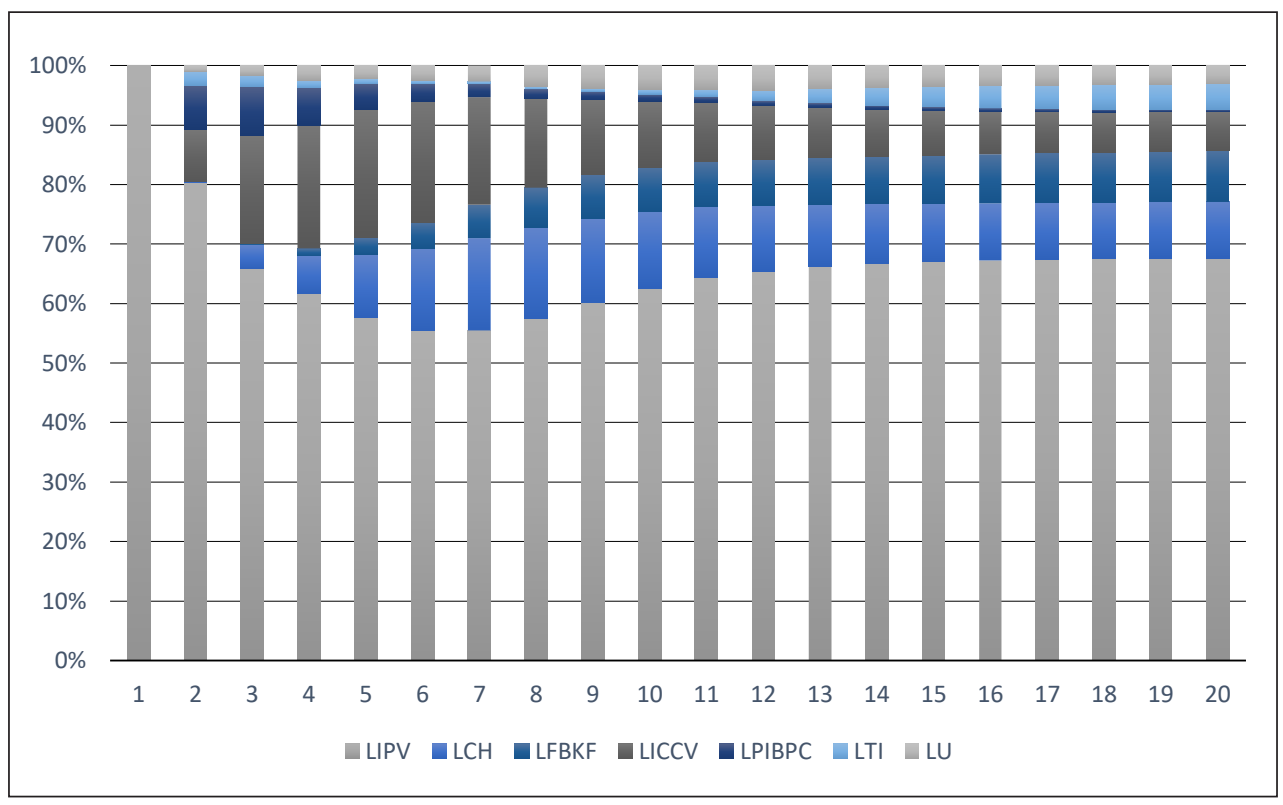

Fuente: elaboración propia

\section{DISCUSIÓN Y CONCLUSIONES}

El mercado inmobiliario en Colombia ha mostrado una dinámica de crecimiento acelerado durante unos ocho años, jalonado en gran medida por el aumento en 
la liquidez y una política expansiva que busca favorecer el crédito. Este contexto lo impulsó el aumento de la inversión extranjera directa proveniente de Estados Unidos y Europa, y las bajas tasas de interés existentes en estos países (producto de la crisis financiera del 2008), dinero que se convirtió en mayor disponibilidad de efectivo y que los bancos suministraron a manera de crédito de diferentes líneas en el mercado.

La política monetaria adoptada por el gobierno permitió un crecimiento de la deuda por encima del 1\% mensual de forma sostenida entre el 2008 y el 2016, lo que impulsó el incremento de la demanda y de los precios de la vivienda -tanto nueva como usada- los cuales se podrían encontrar por encima de su valor real, y que muestra comportamientos compatibles con una dinámica explosiva que se correlaciona con desajustes financieros, tanto internos como externos.

Sin embargo, al endeudamiento elevado se le debe añadir la desaceleración de algunos sectores, lo que da muestra de la fragilidad del proceso experimentado que depende de la generación de empleo estable (para sostener la capacidad de pago de las obligaciones hipotecarias), y de un manejo de política que busque estabilizar de forma suave la dinámica actual. Un incremento del desempleo, o una salida muy fuerte de capitales, tal como la evidenciada desde el 2015, pueden llevar a una caída en los precios de la vivienda, lo cual muestra la debilidad del sector inmobiliario que, una vez empiece su caída, puede traer consigo una crisis de magnitudes comparables a la de finales del siglo XX, cuando factores externos como la crisis asiática y factores internos como el exceso de demanda generaron una contracción en el producto entre 1997 y el 2001, especialmente en aquellas ciudades en las que los precios se elevaron con mayor fuerza durante la fase de auge.

Los resultados econométricos logran validar la hipótesis de insostenibilidad del auge y que este se ha dado de forma especulativa al generar una dinámica de precios dependiente de sí mismos, más que de las condiciones generales de la economía, de las expectativas que crean los agentes alrededor del comportamiento del mercado, de una posible ganancia extraordinaria explicada por la valorización del activo, y del soporte que el mercado crediticio les da a tales expectativas.

Se hace necesario entonces un proceso de intervención que permita estabilizar el mercado y evitar que los desajustes se vuelvan mayores. Si el mercado no se interviene de forma adecuada, será imposible detener la especulación y los costos de adquirir seguirán creciendo para incentivar aún más el endeudamiento, especialmente externo, lo cual agudizará el desbalance externo haciendo más frágil la economía. 


\section{BIBLIOGRAFÍA}

Amico, Fabian; Fiorito, Alejandro y Zelada, Agustina (2012). Expansión económica y sector externo en la Argentina de los 2000: balance y desafíos hacia el futuro. Documento de trabajo n. ${ }^{\circ}$ 45. Buenos Aires, Argentina: CEFID-AR.

Arestis, Philip y González, Ana Rosa (2014). Bank credit and the housing market in OECD countries. En: Journal of Post Keynesian Economics. Vol. 36, No. 3 p. 467-490. doi: 10.2753/ PKE0160-3477360304

Bertocco, Giancarlo (2007). The characteristics of a monetary economy: a Keynes-Schumpeter approach. En: Cambridge Journal of Economics, Vol. 31, No. 1, enero, p. 101-122. doi:

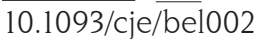

Bertocco, Giancarlo (2011). Housing bubble and economic theory: is mainstream theory able to explain the crisis? Varese, Italy: Faculty of Economics of the University of Insubria, 32p.

Botta, Alberto (2015). The Macroeconomics of a Financial Dutch Disease. Working paper No. 850. New York, United States of America: Levy Economics Institute of Bard College, 24p.

Botta, Alberto; Godin, Antione y Missaglia, Marco (2014). Finance, Foreign (Direct) Investment and Dutch Disease: The Case of Colombia. Working paper No. 853. New York, United States of America: Levy Economics Institute of Bard College, 32p.

Bresser-Pereira, Luiz Carlos (2012). An account of new developmentalism and its structuralist macroeconomics. En: Brazilian Journal of Political Economy, Vol. 31, No. 3(123), julio-septiembre, p. 493-502. doi: http://dx.doi.org/10.1590/S0101-31572011000300010.

Bresser-Pereira, Luiz Carlos (2014). Why Economics Should Be a Modest and Reasonable Science. En: Journal of Economic Issues, Vol. 46, No. 2, p. 291-302. doi: 10.2753/JEI0021-3624460204.

Clavijo, Sergio; Janna, Michel y Muñoz, Santiago (2005). La vivienda en Colombia: sus determinantes socioeconómicos y financieros. En: Revista Uniandes, No. 55, p. 101-165. doi: $10.13043 /$ dys. 55.3

Cynamon, Barry; Fazzari, Steven y Setterfield, Mark (eds.) (2012). After the great recession: the struggle for economic recovery and growth. New York, Unites States of America: Cambridge University Press, 359p.

Fisher, I. (1933). The debt-deflation theory of great depressions, Econometrica 1, p. 337-57. doi:10.2307/1907327

García, José (2009). Crisis económica y dinámica del ajuste inmobiliario en España. País Vasco, España: Unidad de Coordinación Académica de Economía y Empresa. Universidad del País Vasco,16p.

García, José (2010). Financiación inmobiliaria, burbuja crediticia y crisis financiera. Lecciones a partir de la recesión de 2008-2009. En: Papeles de Economía Española. No. 122, p. 66-87.

García, Jhon Jairo; Diaz, Sebastián; Upegui, Juan y Velasquez, Hermilson (2016). Determinantes del precio de la vivienda nueva No VIS en Medellín: un modelo estructural. Working Papers, No. 16-09. En: Centro de Investigaciones Económicas y Financieras, doi: 10.2139/ssrn.2776232 
Goda, Thomas y Torres, Alejandro (2013). Overvaluation of the Real Exchange Rate and the Dutch Disease: The Colombian Case. En: Documentos de trabajo Economía y Finanzas, p. 13-28, 28p. doi: 10.2139/ssrn.2390135

Greene, William (2003). Econometric Analysis. New York, United States of America: Prentice Hall, 1026p.

Hernández, Gustavo y Piraquive, Gabriel (2014). Evolución de los precios de la vivienda en Colombia. En: Archivos de Economía. Documento 407, 43p.

Keen, Steve (2014). Desenmascarando la economía. Ciudad de México, México: Laboratorio de Análisis Económico y Social, LAES, 776p.

Kregel, Jan (2004). External Financing for Development and International Financial Instability. En: G-24 Discussion Paper Series, No. 32, 34p.

Lavoie, Marc (2004). Post Keynesian consumer theory: Potential synergies with consumer research and economic psychology. En Journal of Economic Psychology, Vol. 25, No. 5, p. 639-649. doi: https://doi.org/10.1016/j.joep. 2003.02.001

Lavoie, Marc (2005). La economía postkeynesiana. Un antídoto del pensamiento único. Barcelona, España: Ediciones Icaria,142p.

Lavoie, Marc (2014). Post-Keynesian economics: new foundations. Massachusetts: Edward Elgar Publishing Limited, 660p.

Minsky, Hyman (1986). Stabilizing an unstable economy. New York, United States of America: McGrawHill, 385p.

Minsky, Hyman (1992). The Financial Instability Hypothesis. Working Paper No. 74. New York, United States of America: Levy Economics Institute of Bard College, 10p.

Pérez, Óscar Eduardo (2015). Mercado inmobiliario en Bogotá: ¿̇burbuja en construcción?. En: Laura Amézquita (Ed.), De los Andes al Litoral: estudios sobre vivienda y suelo en Colombia. Bogotá, Colombia: Ediciones Unisalle, p. 167-189.

Salazar, Natalia; Steiner, Roberto; Becerra, Alejandro y Ramírez, Jaime (2013). Los efectos del precio del suelo sobre el precio de la vivienda para Colombia. En: Revista Ensayos sobre Política Económica, Vol. 31, No. 70, p. 17-66.

Sheehan, B.rendan (2009). Understanding Keynes' General Theory. New York, United States of America: Palgrave Macmillan, 278p.

Sorensen, P.; Whitta-Jacobsen, H. (2009). Introducción a la macroeconomía avanzada, Vol. II. Madrid: McGraw-Hill interamericana.

Shiller, Robert (2015). Exuberancia irracional. Barcelona, España: Deusto, 535p.

Tyc, Waldemar (2013). The price bubble morphology. En: Folia Oeconomica Stetinensia, Vol.13, No. 1, p. 76-94. doi: 10.2478/foli-2013-0009. 